\title{
The bacterial alkyltransferase-like (eATL) protein protects mammalian cells against methylating agent-induced toxicity
}

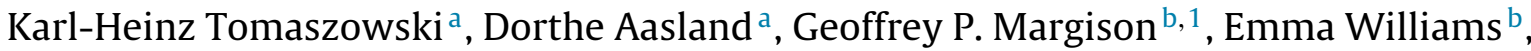 \\ Sarah I. Pinder ${ }^{\mathrm{b}, 2}$, Mauro Modesti ${ }^{\mathrm{c}}$, Robert P. Fuchs ${ }^{\mathrm{c}}$, Bernd Kaina ${ }^{\mathrm{a}, *}$ \\ a Department of Toxicology, University Medical Center, Obere Zahlbacher Strasse 67, D-55131 Mainz, Germany \\ b Paterson Institute for Cancer Research, University of Manchester, Wilmslow Road, Manchester, M20 4BX Manchester, UK \\ ' Centre de Recherche en Cancérologie de Marseille, CNRS-UMR7258, Inserm-U1068, Institut Paoli-Calmettes, Université Aix-Marseille, France
}

\section{A R T I C L E I N F O}

\section{Article history:}

Received 20 August 2014

Received in revised form

13 December 2014

Accepted 22 January 2015

Available online 31 January 2015

\section{Keywords:}

Alkyltransferase

MGMT

ATL

O6MeG

Killing protection

Alkylating agents

\begin{abstract}
A B S T R A C T
In both pro- and eukaryotes, the mutagenic and toxic DNA adduct $O^{6}$-methylguanine $\left(0^{6} \mathrm{MeG}\right)$ is subject to repair by alkyltransferase proteins via methyl group transfer. In addition, in prokaryotes, there are proteins with sequence homology to alkyltransferases, collectively designated as alkyltransferase-like (ATL) proteins, which bind to $O^{6}$-alkylguanine adducts and mediate resistance to alkylating agents. Whether such proteins might enable similar protection in higher eukaryotes is unknown. Here we expressed the ATL protein of Escherichia coli (eATL) in mammalian cells and addressed the question whether it is able to protect them against the cytotoxic effects of alkylating agents. The Chinese hamster cell line CHO-9, the nucleotide excision repair (NER) deficient derivative 43-3B and the DNA mismatch repair (MMR) impaired derivative Tk22-C1 were transfected with eATL cloned in an expression plasmid and the sensitivity to $\mathrm{N}$-methyl- $\mathrm{N}^{\prime}$-nitro-N-nitrosoguanidine (MNNG) was determined in reproductive survival, DNA double-strand break (DSB) and apoptosis assays. The results indicate that eATL expression is tolerated in mammalian cells and conferes protection against killing by MNNG in both wild-type and 43-3B cells, but not in the MMR-impaired cell line. The protection effect was dependent on the expression level of eATL and was completely ablated in cells co-expressing the human $O^{6}$-methylguanine-DNA methyltransferase (MGMT). eATL did not protect against cytotoxicity induced by the chloroethylating agent lomustine, suggesting that $O^{6}$-chloroethylguanine adducts are not target of eATL. To investigate the mechanism of protection, we determined $\mathrm{O}^{6} \mathrm{MeG}$ levels in DNA after MNNG treatment and found that eATL did not cause removal of the adduct. However, eATL expression resulted in a significantly lower level of DSBs in MNNG-treated cells, and this was concomitant with attenuation of G2 blockage and a lower level of apoptosis. The results suggest that eATL confers protection against methylating agents by masking $\mathrm{O}^{6} \mathrm{MeG}$ /thymine mispaired adducts, preventing them from becoming a substrate for mismatch repair-mediated DSB formation and cell death.
\end{abstract}

(C) 2015 Elsevier B.V. All rights reserved.

\section{Introduction}

DNA is known to contain various types of alkylation damage that are presumed to arise from exposure to exogenous chemical agents or endogenously as by-products of cellular metabolism [1]. One of the lesions found in DNA as a result of the reaction with

\footnotetext{
* Corresponding author. Tel.: +49 613117 9217; fax: +49 6131178499.

E-mail address: kaina@uni-mainz.de (B. Kaina).

1 Current address at: Centre for Occupational and Environmental Health, Faculty of Medical \& Human Sciences, University of Manchester, Manchester M13 9PL, UK.

2 Current address at: Genome Damage and Stability Centre, University of Sussex, Falmer, Brighton BN1 9QG, UK.
}

methylating species is $O^{6}$-methylguanine $\left(\mathrm{O}^{6} \mathrm{MeG}\right)$, a highly mutagenic and cytotoxic DNA lesion [2]. $\mathrm{O}^{6} \mathrm{MeG}$ exerts its mutagenic effect through mispairing with thymine during DNA replication, leading after a further round of DNA replication to $G: C$ to A:T transition mutations $[3,4]$. The cytotoxic effect of $\mathrm{O}^{6} \mathrm{MeG}$ stems from the binding of the mismatch repair (MMR) protein MutS $\alpha$, a dimer composed of $\mathrm{MSH} 2$ and $\mathrm{MSH}$, to $\mathrm{O}^{6} \mathrm{MeG}$ :T mispairs. This initiates binding of other MMR proteins and the excision of the misincorporated thymine, but due to the mispairing properties of $\mathrm{O}^{6} \mathrm{MeG}$, thymine is reinserted opposite $\mathrm{O}^{6} \mathrm{MeG}$, resulting in futile cycles of MMR along with extended DNA single-strand gaps [5]. Replication of DNA containing these structures generates DNA double-strand breaks (DSBs), which trigger cell death by activating apoptosis pathways [6-8]. The more complex DNA 
adduct, $O^{6}$-chloroethylguanine $\left(\mathrm{O}^{6} \mathrm{ClEtG}\right)$, which is generated by chemotherapeutic chloroethylnitrosoureas (CNUs) such as lomustine (CCNU), is also cytotoxic. However, induction of cell death following CNUs occurs in an MMR independent manner [9]. Thus, intramolecular rearrangement of the $\mathrm{O}^{6} \mathrm{ClEtG}$ adduct leads ultimately to the formation of an N1-guanine-N3-cytosine interstrand crosslink (ICL) [10], which blocks replication, resulting in collapse of replication forks and the formation of DSBs [11].

The potential lethal effects of $O^{6}$-guanine alkylation damage have likely resulted in the evolution and conservation in proand eukaryotes of various strategies to eliminate the damage from DNA. One such mechanism, in all species except plants, involves the removal of the alkyl group by alkyltransferases (for human cells $O^{6}$-methylguanine-DNA methyltransferase (MGMT) [9]). These proteins bind to $O^{6}$-alkylguanine adducts in DNA and transfer the alkyl group to an internal cysteine residue in an autoinactivating stoichiometric process leading ultimately to proteasomal degradation [12]. In addition, in bacteria and yeast, there are proteins with some sequence homology to AGTs, collectively designated as alkyltransferase-like (ATL) proteins. Where examined, these proteins exhibit no alkyltransferase activity $[13,14]$, but are able to bind to a wide variety of $O^{6}$-alkylguanine lesions $[13,15]$ and confer resistance to the toxic and mutagenic effects of alkylating agents $[16,17]$.

The protective effect of ATL proteins has been attributed to binding to the damaged DNA strand, which results in DNA bending and base flipping and the recruitment of nucleotide excision repair (NER) proteins that eliminate the $O^{6}$-alkylguanine adduct $[18,19]$. In Schizosaccharomyces pombe, the alkyltransferase-like protein 1 (Atl1) targets $\mathrm{O}^{6} \mathrm{MeG}$ for global genome NER, whereas transcription-coupled NER participates in the repair of more complex adducts [20]. The ATL of Escherichia coli, initially described as ybaZ [21], was not only reported to initiate NER [17], but also to mask DNA damage and thus prevents the conversion of certain $O^{6}$-alkylguanines to toxic lesions by the MMR system [22]. This process was shown to reduce the transforming effect in $E$. coli of a plasmid containing $O^{6}$-hydroxyethyl-, $O^{6}$-1-hydroxypropyl- and $0^{6}$-2-hydroxypropylguanine, but not $0^{6} \mathrm{MeG}$, albeit at the cost of a higher mutation frequency [22]. It was therefore proposed to be a lethality avoidance mechanism by damage tolerance.

ATL proteins, that is, $O^{6}$-alkylguanine sensing proteins that have no inherent catalytic activity but support the repair of $0^{6}$ alkylguanine adducts, have not so far been reported in mammalian cells. $\mathrm{O}^{6} \mathrm{MeG}$ is a highly mutagenic and cytotoxic adduct, and, given that prokaryotes have evolved different strategies for removing this lesion from DNA, it is remarkable that mammalian cells appear to have only a single protein, MGMT, responsible for its repair. It might be speculated that mammalian cells either do not need a backup system for repairing $\mathrm{O}^{6} \mathrm{MeG}$ (in which ATL is involved) or do not tolerate protein(s) with ATL function that probe the DNA for the presence of $O^{6}$-alkylguanines and support their repair. It was therefore of interest to investigate whether the expression of ATL in mammalian cells is tolerable and whether it impacts the effects of simple alkylating agents in cells that do not express MGMT. To examine the possible effects of ATL expression in mammalian cells, we introduced the ATL protein of E. coli, in the following referred to as eATL, into Chinese hamster cells and exposed them to alkylating agents. We show that expression of eATL is well tolerated, having no impact on cell proliferation and survival. It protects against cytotoxicity induced by $\mathrm{N}$-methyl-N'-nitro-N-nitrosoguanidine (MNNG), but not lomustine (CCNU). Intriguingly, eATL expressing cells did not demonstrate increased capacity to eliminate $\mathrm{O}^{6} \mathrm{MeG}$ from DNA. However, they showed a reduced number of DSBs, attenuated G2 arrest and apoptosis following MNNG indicating that protection against killing occurred by preventing the action of MMR on $\mathrm{O}^{6} \mathrm{MeG}: \mathrm{T}$ mispairs induced in replicating cells.

\section{Materials and methods}

\subsection{Cell culture and drug treatment}

The wild-type Chinese hamster cell line, CHO-9, the corresponding ERCC1 mutant 43-3B (NER-deficient) [23,24], the MMR-impaired derivative Tk22-C1 (designated originally as strain Tk22cos9/5-1/2-C1 [25]) and a CHO-9 derivative stably transfected with the human MGMT cDNA [26] were used in this study. All cell lines were cultured with Dulbecco's MEM/F-12 medium (1:1) containing $5 \%$ foetal calf serum (FCS) and penicillin (100 unit $/ \mathrm{ml}$ ) and streptomycin $(100 \mu \mathrm{g} / \mathrm{ml})$ in a humidified atmosphere in $7 \%$ $\mathrm{CO}_{2}$ at $37^{\circ} \mathrm{C}$. MNNG (Sigma, Munich, Germany) was dissolved in dimethylsulfoxide (DMSO) and then diluted with sterile water to a final concentration of $10 \mathrm{mM}$. A solution of $10 \mathrm{mM}$ lomustine [1-(2chloroethyl)-3-cyclohexyl-L-nitrosourea; CCNU] (Sigma, Munich, Germany) was prepared by dissolving in ethanol. Aliquots of MNNG and $\mathrm{CCNU}$ were stored at $-80^{\circ} \mathrm{C}$ and $-20^{\circ} \mathrm{C}$, respectively. For the treatment of exponentially growing cells MNNG or CCNU was added directly to the medium.

\subsection{Plasmid constructions and transfection}

The eATL pcDNA3.1 vector (containing a neomycin resistance cassette) was generated using the pcDNA3.1/V5 His Topo TA Expression Kit (Invitrogen, Darmstadt, Germany) according to the provided protocol. The eATL cassette was isolated by PCR using the vector pMBP-YbaZ [22] as template and eATL forward: 5'-GCCATGCGACTTCACTCGGGC-3'; reverse: 5'TCAGTAGTTCCAGCGATAACG-3' primers. The version of eATL pcDNA3.1 containing a hygromycin resistance cassette was obtained by excision of the eATL sequence with Hind III and Xho I from the eATL pcDNA3.1 (neomycin) vector and insertion into the Hind III-Xho I digested pcDNA3.1 (hygromycin) vector. The Effectene transfection kit (Qiagen, Hilden, Germany) was used for transient transfection of Tk22-C1 cells and to stably transfect $\mathrm{CHO}$ 9 and 43-3B cells with the eATL pcDNA.3.1 neomycin vector, as well as AT17-C3 cells with the eATL pcDNA.3.1 hygromycin vector. After transient transfection Tk22-C1 cells were allowed to regenerate before initiation of experiments. To obtained stably transfected clones cells were grown in media containing $1.5 \mathrm{mg} / \mathrm{ml} \mathrm{G} 418$ (CHO$9,43-3 \mathrm{~B}$ ) or $0.8 \mathrm{mg} / \mathrm{ml}$ hygromycin $\mathrm{B}$ and resistant clones were selected. Transfectants were routinely cultured in selective media, but the selective agents were omitted during the experiments.

\subsection{Polymerase chain reaction}

Total RNA from cultured cells was isolated using the Nucleospin RNA II Kit (Macherey-Nagel, Düren, Germany). One microgram RNA was transcribed into cDNA using the Verso cDNA Kit (Thermo Scientific, St. Leon-Rot, Germany). PCR amplification was performed using Red-Taq Ready Mix (Sigma-Aldrich, Taufkirchen, Germany) and primers for eATL (forward: 5'-TCGCCACGGCACAATTTCGC-3', reverse: $5^{\prime}$-AGTCGATTTGCCCGCTTCCCG-3') and $\beta$-Actin (forward: 5'-GCTCTTTTCCAGCCTTCCTT-3', reverse: 5'-GAGCCAGAGCAGTG ATCTCC $\left.-3^{\prime}\right)$.

\subsection{Antibody production}

Anti-eATL polyclonal antibodies were obtained by immunisation of rabbits (Eurogentec) with recombinant MBP-eATL and purified by protein A affinity chromatography.

\subsection{Preparation of cell extracts and western blotting}

To achieve a probable accumulation of eATL protein in the nucleus (through binding of eATL to $\mathrm{O}^{6} \mathrm{MeG}$ ), cells were treated 
with MNNG (10 $\mu \mathrm{M}$ MNNG, $1 \mathrm{~h})$. AT17-C3 and their corresponding eATL clone underwent pre-treatment $(1 \mathrm{~h})$ with $10 \mu \mathrm{M}$ $O^{6}$-benzylguanine for depletion of MGMT. Nuclear extracts were prepared and western blot analysis was performed as previously described [27]. Protein was visualised using the Odyssey system (LI-COR Biosciences). The following antibodies were used: anti-eATL (dilution 1:25); $\beta$-actin (dilution 1:4.000, Santa Cruz, Heidelberg, Germany) and donkey fluorophor-coupled secondary antibody (dilution 1:5.000, LI-COR Biosciences).

\subsection{Colony formation assay}

The colony formation assay was performed as previously described [28]. Briefly, exponential growing cells were seeded, allowed to attach for $6 \mathrm{~h}$ and treated with varying concentrations of alkylating agents. After incubation for 8 or 10 days, colonies were fixed, stained and counted.

\subsection{Determination of apoptosis and necrosis}

Induction of apoptosis or necrosis was determined by annexin V-FITC/propidium iodide (PI) staining and flow cytometry (FACSCanto, Becton Dickinson, Heidelberg, Germany) as previously described [27].

\subsection{Quantification of $\mathrm{O}^{6} \mathrm{MeG}$}

DNA was extracted from cell pellets and analysed for $0^{6} \mathrm{MeG}$ content by an MGMT competitive inactivation method as previously described [29].

\subsection{Proliferation and cell cycle analysis}

Cell proliferation status was assessed by flow cytometry to quantify the mean fluorescence intensity (MFI) of carboxyfluorescein diacetate succinimidyl ester (CFSE) as previously described [8]. Briefly, cells $\left(1 \times 10^{6}\right.$ cells $\left./ \mathrm{ml}\right)$ were labelled in PBS containing $5 \mu \mathrm{M}$ CFSE (Sigma, Munich, Germany) for $8 \mathrm{~min}$ at room temperature in the dark. Residual CFSE was quenched by adding 5 volumes FCS. Cells were washed twice with PBS and seeded in $60 \mathrm{~mm}$ cell culture dishes for $24 \mathrm{~h}$. Following non-treatment or treatment with $10 \mu \mathrm{M}$ MNNG for $1 \mathrm{~h}$ at $37^{\circ} \mathrm{C}$ (defined as zero time, and 100\% CFSE signal) and subsequent incubation for various times, cells were harvested and re-suspended in PBS with $16.7 \mu \mathrm{g} / \mathrm{ml}$ PI for $5 \mathrm{~min}$ at room temperature in the dark. Flow cytometry was performed using a FACSCanto (Becton Dickinson, Heidelberg, Germany). To analyse cell cycle progression, adherent cells were harvested and fixed in $70 \%$ ice cold ethanol for at least $30 \mathrm{~min}$. After RNAase $(30 \mu \mathrm{g} / \mu \mathrm{l})$ digestion, DNA was stained with PI $(16.7 \mu \mathrm{g} / \mathrm{ml})$ in PBS. Samples were analysed by flow cytometry and the proportion of cells in each phase of the cell cycle were calculated using ModFitTM.

\subsection{Fluorescence microscopy}

Cells were seeded on cover slips, treated with MNNG $(1 \mu \mathrm{M}$, $24 \mathrm{~h}$ ) and prepared for yH2AX immunostaining. Cells were fixed in $4 \%$ formaldehyde-PBS and then ice-cold $100 \%$ methanol was added. For LSM, fixation occurred in methanol:acetone $(v / v, 7: 3)$ at $-20^{\circ} \mathrm{C}$. Non-specific binding of antibodies was avoided by blocking with $5 \%$ BSA in $0.3 \%$ Triton X-PBS. Cells were incubated with the primary antibody (mouse anti-phospho-H2A.X, Millipore, 1:1000) at $4{ }^{\circ} \mathrm{C}$ overnight followed by incubation with secondary antibody (anti-mouse Alexa Fluor 488, Invitrogen, 1:500) at room temperature. Nuclei were counterstained with $100 \mathrm{nM}$ DAPI (quantification of $\mathrm{yH} 2 \mathrm{AX}$ ) or $1 \mu \mathrm{M}$ TO-Pro-3 (representative example) and slides
Table 1

Cell lines, their repair status and population doubling times.

\begin{tabular}{lll}
\hline Cell line & Repair status & Doubling time $(\mathrm{h})$ \\
\hline CHO-9 & Wild-type & $11.6 \pm 1.2$ \\
CHO eATL Cl. 3 & eATL proficient & $10.6 \pm 1.2$ \\
CHO eATL Cl. 4 & eATL proficient & $13.0 \pm 0.5$ \\
43-3B & ERCC1 mt (NER deficient) & $11.7 \pm 1.4$ \\
43-3B eATL Cl. 1 & eATL proficient + NER deficient & $12.7 \pm 1.8$ \\
AT17-C3 & MGMT proficient & $10.5 \pm 1.3$ \\
AT17 eATL Cl. 4 & MGMT and eATL proficient & $10.5 \pm 1.4$ \\
Tk22-C1 & MMR impaired (decline of MSH2) & $13.8 \pm 0.3$ \\
Tk22-C1 eATL & eATL proficient + MMR impaired & $13.3 \pm 0.4$ \\
\hline
\end{tabular}

were mounted in VECTASHIELD (Vector Laboratories). For quantification, foci were automatically scored by fluorescent microscopy using the Metafer Finder System v. 3.1 (MetaSystems). Representative examples for $\mathrm{yH} 2 \mathrm{AX}$ staining were acquired by confocal microscopy (LSM 710; Carl Zeiss).

\subsection{Neutral comet assay}

The procedure for detection of DSBs by neutral single-cell gel electrophoresis was performed as previously described [6]. Analysis of DNA migration occurred by means of an image analysis system (Komet 4.0.2; Optilas) and head/tail intensity of at least 50 cells per sample was determined.

\section{Results and discussion}

To determine the effect of eATL on the response of mammalian cells to alkylating agents, we transfected eATL into Chinese hamster cells and selected stably transfected clones. We used the wildtype CHO-9, its NER-defective mutant 43-3B (mutated in ERCC1) and the MGMT-overexpressing CHO-9 transfectant AT17-C3. RTPCR of RNA isolated from G418 and hygromycin B resistant clones confirmed the expression of eATL (Fig. 1A) and western blotting demonstrated that the transfectants expressed detectable amounts of eATL (Fig. 1B). Two independent clones of CHO-9 showed different levels of expression of eATL on protein level, designated as $\mathrm{Cl}$. 3 and $\mathrm{Cl}$. 4 (Fig. 1B). Expression was stable during the course of the experiments. We also performed transient transfection experiments with the isogenic MMR-impaired cell line Tk22-C1. The expression of eATL mRNA (Fig. 1C) and protein (Fig. 1D) was confirmed $24 \mathrm{~h}$ after transfection. It remained still detectable 7 days thereafter (not shown). The eATL protein had no significant impact on the proliferation rate of the cells (Table 1 ).

In colony forming experiments, $\mathrm{CHO}-9$ cells expressing eATL were clearly more resistant to MNNG than the parental line, and CHO-9 eATL Cl. 3 was more resistant than CHO-9 eATL Cl. 4 (Fig. 2A), which correlated with the eATL protein expression level (Fig. 1B). The CHO-9 derived mutant 43-3B did not differ significantly from the parent cell line in its sensitivity to MNNG (Fig. 2A and B), which was expected as ERCC1 is not involved in the repair of MNNGinduced DNA lesions [30]. Expression of eATL in 43-3B cells again resulted in enhanced survival rate, closely similar to those seen in CHO-9 eATL Cl. 3 (Fig. 2A and B), indicating that eATL provokes MNNG resistance independent of NER. CHO-9 cells do not express MGMT and expression of MGMT in the AT17-C3 cell line conferred a significant increase in resistance to MNNG versus $\mathrm{CHO}-9$. Additional expression of eATL neither increased nor decreased MNNG resistance (Fig. 2C), indicating that eATL operates independently of MGMT in mammalian cells. We should note that eATL, due to its binding affinity to $O^{6} \mathrm{MeG}$, reduces the capacity of MGMT for repairing the adduct, which was shown in assays in vitro [13]. The possible competition of eATL with MGMT in the context of the chromatin in vivo (in mammalian cells) remains to be elucidated. 
A

eATL

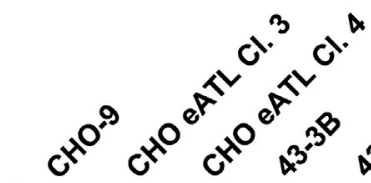

B-Actin

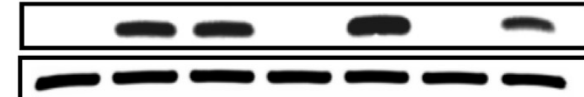

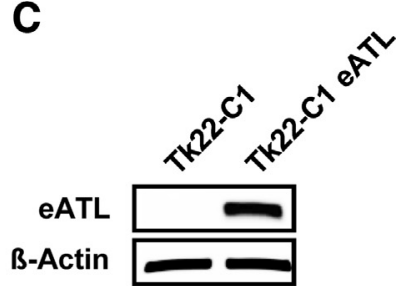

D

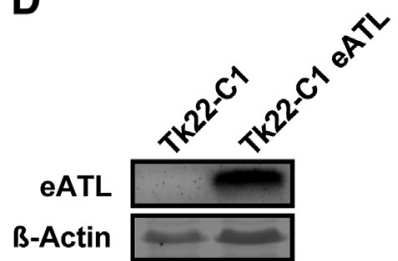

Fig. 1. Expression of eATL in stably and transiently transfected cell lines. CHO cells were transfected with eATL-expression vector and selected for G418 or hygromycin B resistance to obtained stable clones. Expression was confirmed by RT-PCR of mRNA ( $A$ and $C$ ) and western blot analysis of nuclear protein (B and D). For transient transfection, mRNA and protein level of eATL were analysed $24 \mathrm{~h}$ after transfection ( $C$ and D). $\beta$-Actin served as loading control.
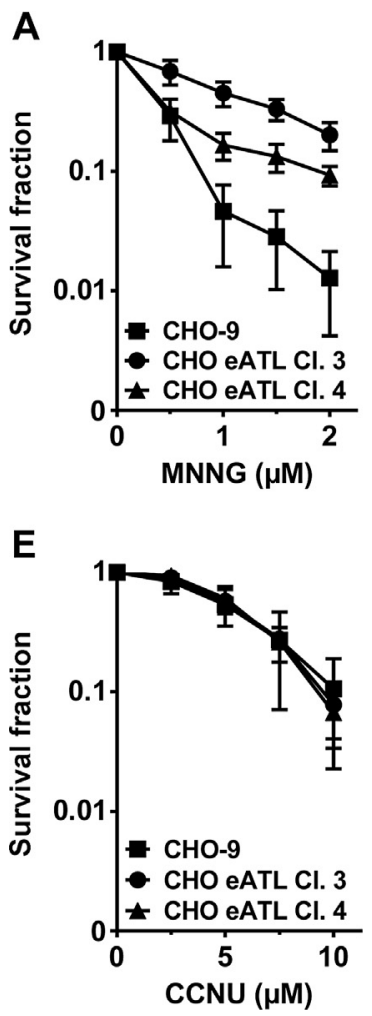
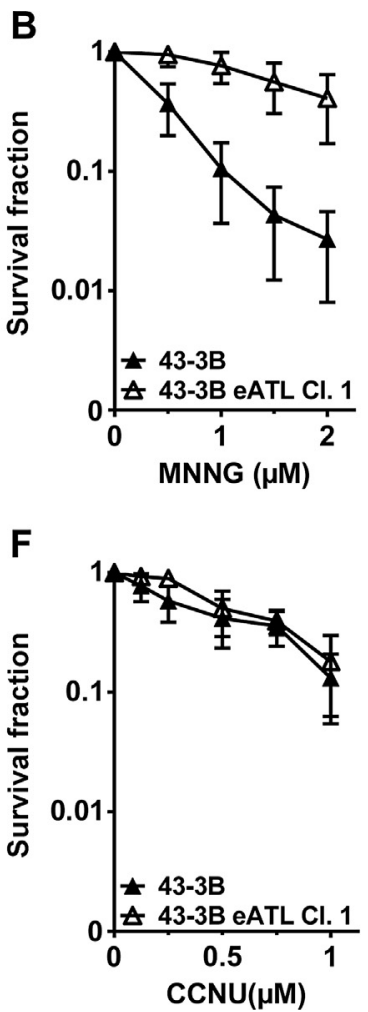
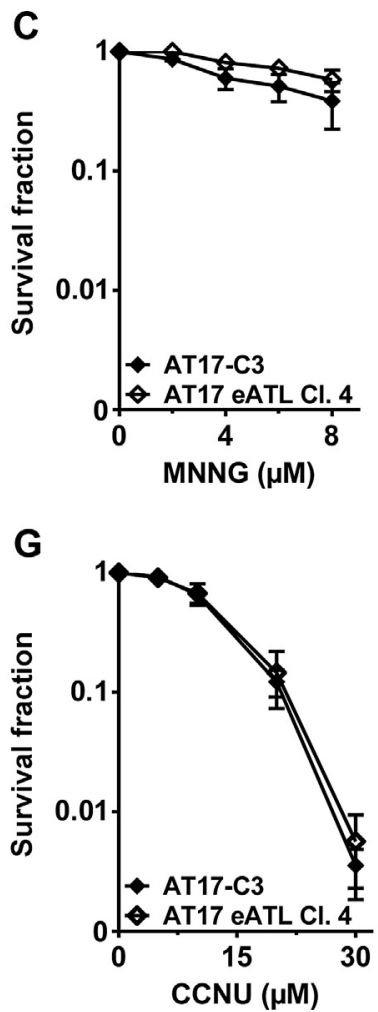

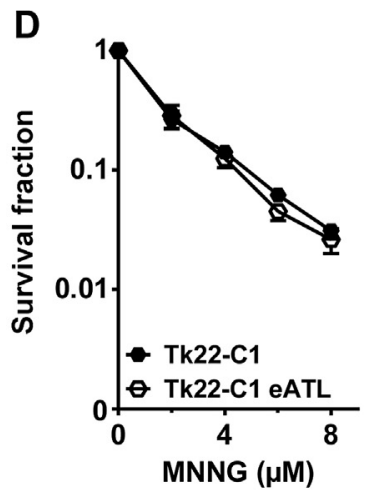

H

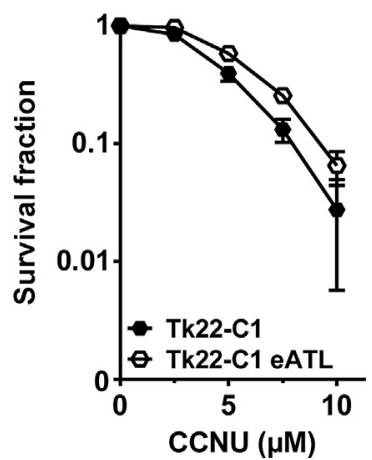

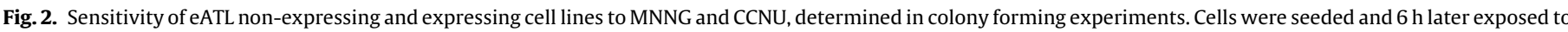

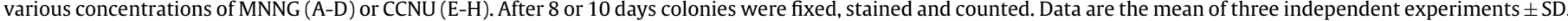
The measure points for eATL transfectants compared to the parental cells shown in panel A and B are highly significant $(p<0.05)$.

Survival experiments were also performed with Tk22-C1 cells derived from $\mathrm{CHO}-9$, which are characterised by downregulation of MSH2 expression (20\% MSH2 protein compared to the wild-type) and increased MNNG resistance [25]. Expression of eATL in Tk22C1 (Fig. 1C and D) did not change their response to MNNG (Fig. 2D), indicating that under MMR-impaired conditions eATL does not confer protection.

A critical cytotoxic lesion induced in DNA by chloroethylating agents is $\mathrm{O}^{6}$-chloroethylguanine $\left(\mathrm{O}^{6} \mathrm{ClEtG}\right)$, which is also a substrate for MGMT. Therefore, we examined if eATL would have an impact on the cytotoxicity of this lesion. eATL expression had no effect on the sensitivity of either CHO-9 (Fig. 2E) nor 43-3B cells (Fig. 2F) to CCNU, suggesting that eATL has no impact on the repair of $\mathrm{O}^{6} \mathrm{ClEtG}$ adducts. Of note, the NER-defective cell line 43-3B and the corresponding eATL clone showed much greater sensitivity to the chloroethylating agent than $\mathrm{CHO}-9$ cells (note the much lower concentration of CCNU used for these cells) due to their inability to repair interstrand crosslinks (ICL), arising from $\mathrm{O}^{6} \mathrm{ClEtG}$ adducts; ICL repair requires the involvement of functional NER [31]. In contrast, AT17-C3 cells (expressing MGMT) were clearly more resistant 

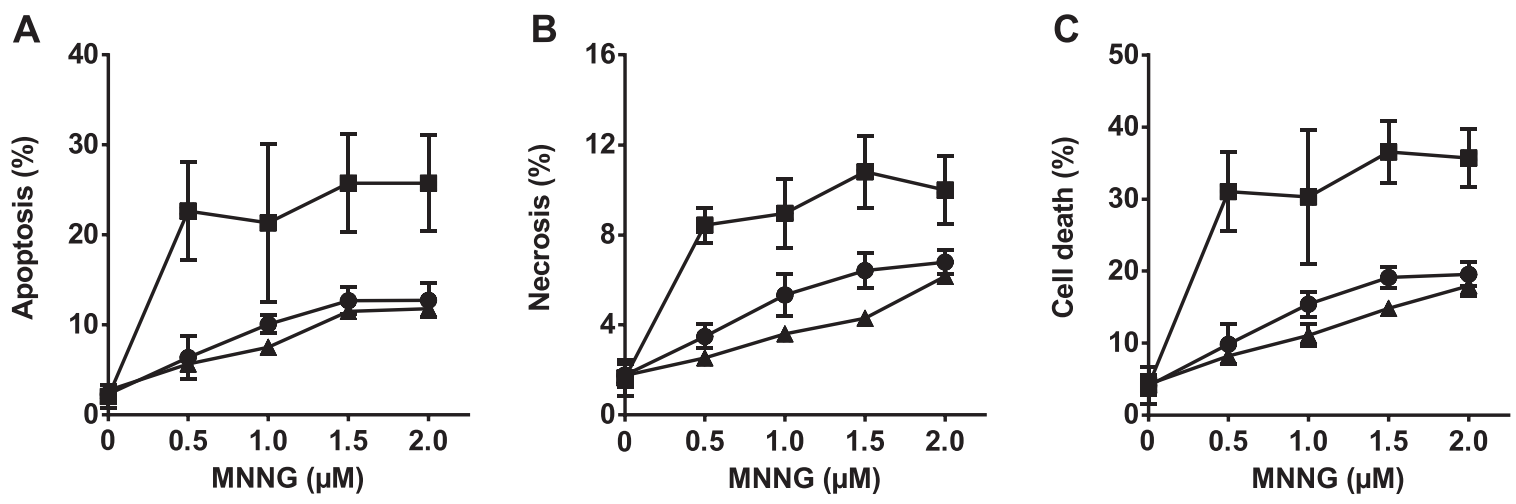

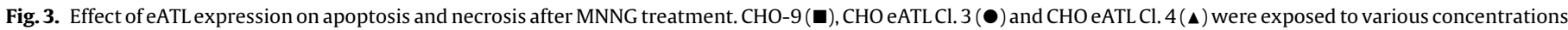
of MNNG and annexin V/PI analyses were performed by flow cytometry $72 \mathrm{~h}$ after treatment. Data are the mean of three independent experiments \pm SD.

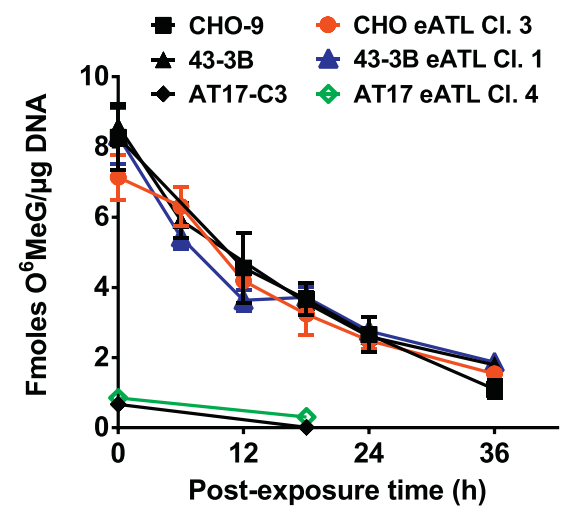

Fig. 4. Repair kinetics of $\mathrm{O}^{6} \mathrm{MeG}$. The cell lines indicated were treated with $10 \mu \mathrm{M}$ MNNG for $1 \mathrm{~h}$. Levels of $O^{6} \mathrm{MeG}$ in the DNA were determined immediately after treatment $(0 \mathrm{~h})$ and over a period of $36 \mathrm{~h}$ post-treatment.

to CCNU (Fig. 2G compare with Fig. 2E: note the change of scale of the $\mathrm{X}$ axis). The death of MGMT-expressing cells at high dose CCNU treatment is likely the result of $\mathrm{N}$-chloroethylations, which are less toxic than $\mathrm{O}^{6} \mathrm{ClEtG}$ [11]. Again, the expression of eATL in these cells had no impact on cell survival following CCNU treatment (Fig. 2G). The sensitivity of the MMR-impaired cell line Tk22-C1 to CCNU was comparable to CHO-9 cells, supporting the notion that cytotoxicity provoked by chloroethylating agents is MMR-independent. Expression of eATL in Tk22-C1 had no clear impact on their response to CCNU (Fig. 2H), suggesting, together with the results obtained for CHO-9 and 43-3B transfectants, that eATL does not influence the repair of $\mathrm{O}^{6} \mathrm{ClEtG}$.

Cell death following MNNG treatment in $\mathrm{CHO}-9$ cells is the result of apoptosis triggered by $\mathrm{O}^{6} \mathrm{MeG}[6]$, although some necrosis can also be induced [32]. The level of apoptosis and necrosis following increasing doses of MNNG in CHO-9 cells, $\mathrm{CHO}$ eATL $\mathrm{Cl}$. 3 and $\mathrm{CHO}$ eATL Cl. 4 is shown in Fig. $3 \mathrm{~A}$ and $\mathrm{B}$, respectively. Fig. $3 \mathrm{C}$ shows the effect of increasing doses of MNNG on total cell death. The data shows that eATL-expressing cells are more resistant to MNNGinduced apoptosis and necrosis. This confirms the notion that eATL protects against $\mathrm{O}^{6} \mathrm{MeG}$, which is the major death triggering lesion in cells lacking MGMT [9].

In mammalian cell, the only known repair mechanism for $\mathrm{O}^{6} \mathrm{MeG}$ is MGMT and, therefore, in cells lacking MGMT, $\mathrm{O}^{6} \mathrm{MeG}$ is a persistent DNA lesion [33]. To examine the possibility that eATL enables the removal of $\mathrm{O}^{6} \mathrm{MeG}$ from DNA, we measured the amount of $\mathrm{O}^{6} \mathrm{MeG}$ in $\mathrm{CHO}-9$ wild-type, 43-3B and AT17-C3 cells in the absence and presence of eATL immediately and up to $36 \mathrm{~h}$ after pulse treatment $(1 \mathrm{~h})$ with $10 \mu \mathrm{M}$ MNNG. As shown in Fig. 4, the amount of $\mathrm{O}^{6} \mathrm{MeG}$ was, as anticipated, significantly lower in
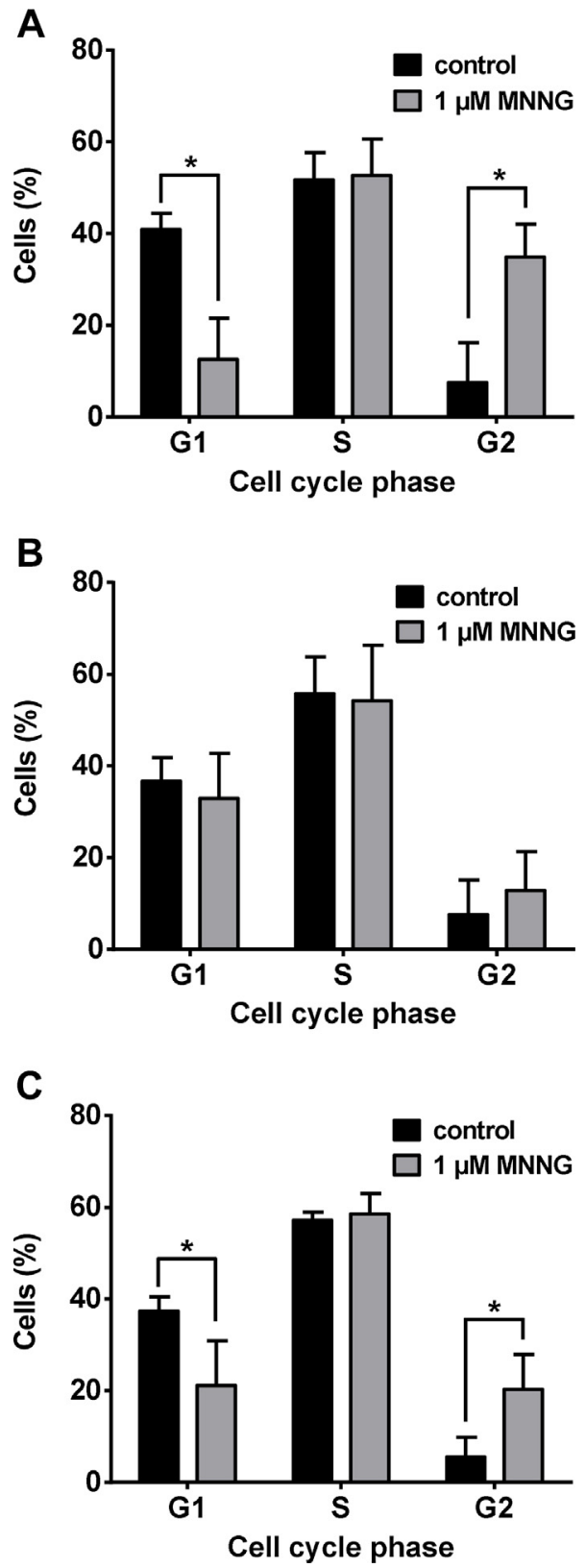

Fig. 5. Cell cycle progression following exposure to MNNG. (A) CHO-9 cells, (B) CHO eATL Cl. 3 and (C) CHO eATL Cl. 4 were treated with $1 \mu \mathrm{M}$ MNNG and the proportion of cells in each cell cycle phase was quantified $24 \mathrm{~h}$ later by flow cytometry. Data are the mean of three independent experiments. ${ }^{*} p<0.01$. 
AT17-C3 cells (MGMT expressing) compared to the other isogenic lines and declined to undetectable levels when measured $18 \mathrm{~h}$ later. Most importantly, in all other cell lines lacking MGMT, the $\mathrm{O}^{6} \mathrm{MeG}$ level was high immediately after treatment and declined at the same rates in parental cells and transfectants, as determined up to $36 \mathrm{~h}$ after treatment. This decline is the result of dilution of the DNA damage by cell proliferation, which was similar in all of the cell lines (data not shown). Overall, the data indicate that eATL has no impact on the removal of $\mathrm{O}^{6} \mathrm{MeG}$ from DNA, despite the observation that it strongly impacts on the killing effects of this lesion.

The current model for the mechanism of cell killing by $\mathrm{O}^{6} \mathrm{MeG}$ suggests that replication of DNA containing this lesion results in an $\mathrm{O}^{6} \mathrm{MeG}$ : $\mathrm{T}$ mispair, which is recognised by MMR proteins. MMR processing of this mismatch conserves the $\mathrm{O}^{6} \mathrm{MeG}$ adduct, but causes the persistence of long single-strand gaps in the DNA which, on the second round of replication, lead to collapse of replication forks, DSB formation and cell death [8]. eATL has been shown to bind to both $\mathrm{O}^{6} \mathrm{MeG}: \mathrm{C}$ base pairs and $\mathrm{O}^{6} \mathrm{MeG}$ : $\mathrm{T}$ mismatches [22], so one possibility is that eATL binding to the mismatch blocks the access of MutS $\alpha$, ultimately preventing the formation of DSB. To explore this hypothesis, we first analysed cell cycle progression following MNNG treatment, since $0^{6} \mathrm{MeG}$ processing by MMR results in CHO-9 cells in a $\mathrm{G} 2$ arrest in the 2 nd post-treatment cell cycle [8]. As shown in Fig. 5A, treatment of $\mathrm{CHO}-9$ cells caused a highly significant reduction of cells in G1 and an accumulation in G2 phase $24 \mathrm{~h}$ later. In contrast, eATL-expressing cells showed a reduced G2 block after MNNG treatment depending on their eATL expression level (Fig. 5B and C). Thus, treatment of CHO eATL Cl. 4 caused a moderate accumulation in G2 phase (20\% compared to $35 \%$ in the wild-type), whereas in $\mathrm{CHO}$ eATL $\mathrm{Cl} .3$ cells there was no significant difference between untreated and MNNG-treated cells, demonstrating that eATL expression ablated the effects of MNNG on the cell cycle.

If eATL prevents $\mathrm{O}^{6} \mathrm{MeG}$ :T mispairs from being processed by MMR proteins, which is required for DSB formation [6], we posited that DSBs will not be formed or formed at a lower level in the presence of eATL. To this end, we assessed the formation of $\gamma \mathrm{H} 2 \mathrm{AX}$ foci, a sensitive marker for DSBs [34], and also performed the neutral comet assay, which is an established method for DSB detection [35]. Representative photomicrographs of untreated and MNNG-treated CHO-9 and eATL-expressing cells are shown in Fig. 6A. Quantification showed a significantly lower number of $\gamma \mathrm{H} 2 \mathrm{AX}$ foci per cell (Fig. 6B) and a significantly lower fraction of cells with a high number of foci $(>30)$ per cell in the MNNG resistant eATL-expressing population (Fig. 6C). Additionally, we observed in the neutral comet assay in eATL expressing cells a significantly lower tail intensity following MNNG, compared to CHO-9 (Fig. 6D). This supports the notion that eATL reduces the yield of DSBs in cells treated with MNNG.

In summary, we demonstrate that mammalian cells tolerate the expression of eATL and that eATL confers protection against the killing effect of the $O^{6}$-methylating agent MNNG. While eATL expression did not affect the persistence of $\mathrm{O}^{6} \mathrm{MeG}$ in MGMT lacking cells treated with MNNG, we show that the level of apoptosis and necrosis and the frequency of DSBs triggered by $\mathrm{O}^{6} \mathrm{MeG}$ were significantly reduced in the presence of eATL. These observations are consistent with the hypothesis that eATL masks the $0^{6} \mathrm{MeG}: \mathrm{T}$
A
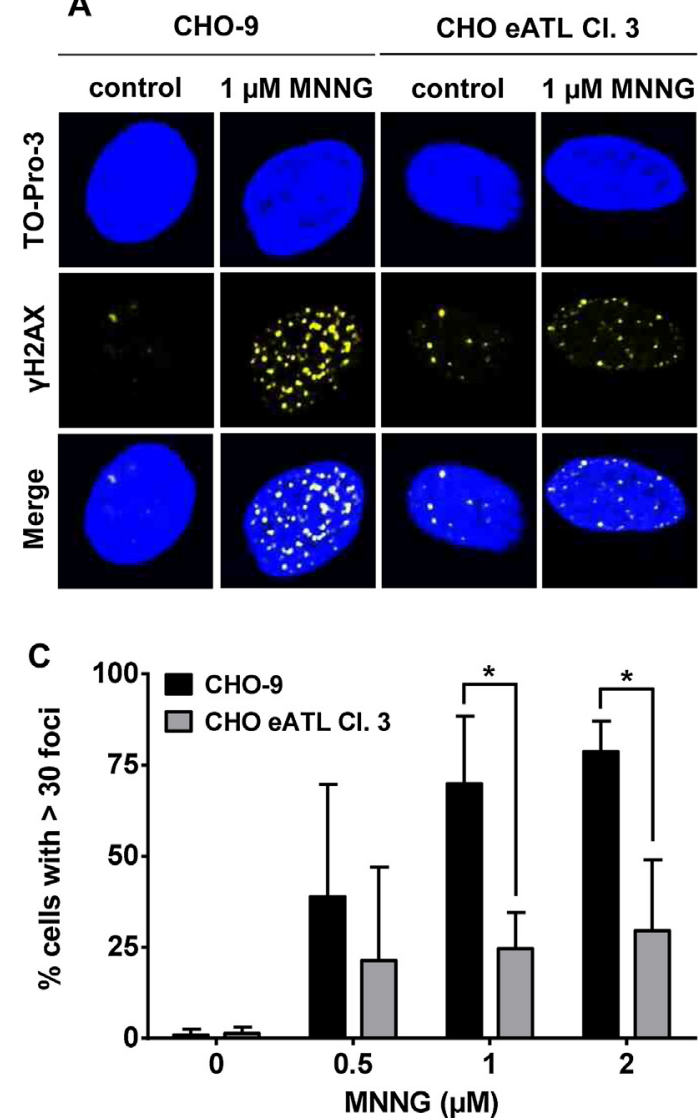

B
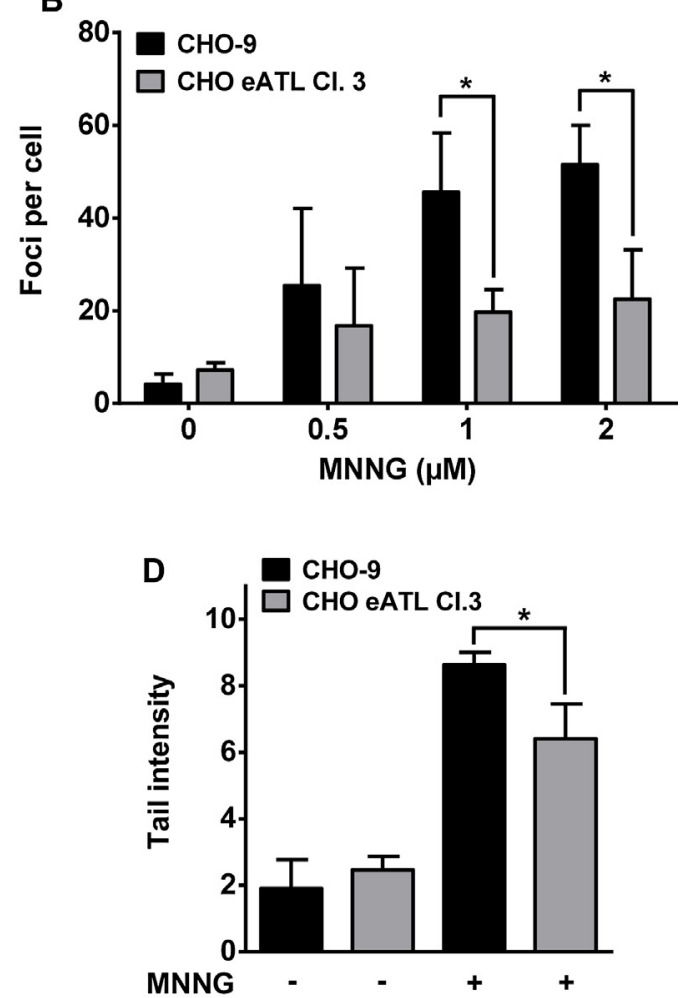

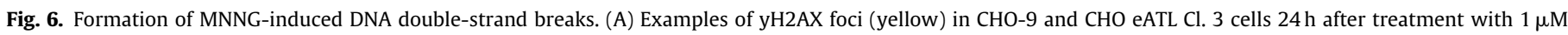

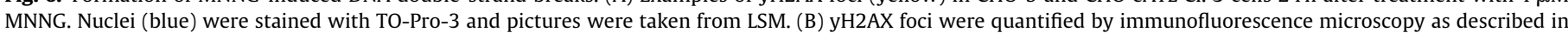

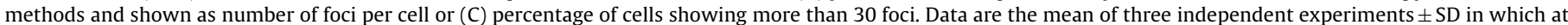

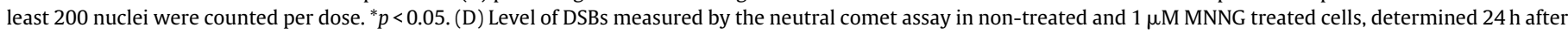
treatment. The level of DNA breakage was expressed by the relative tail intensity. ${ }^{*} p<0.05$. 
mispairs and therefore prevents them from being converted by futile MMR cycles and replication into cytotoxic DSBs. The finding that in MMR impaired cells eATL was ineffective, as it did not further enhance the resistance to MNNG, supports this notion. In experiments with $E$. coli the eATL (YbaZ) protein was shown to bind to $\mathrm{O}^{6} \mathrm{MeG} / \mathrm{T}$ and also to larger $\mathrm{O}^{6}$ alkylguanine adducts. However, it supported only at low efficiency the rescue of a plasmid containing the $\mathrm{O}^{6} \mathrm{MeG}$ adduct in a cell transformation assay [22]. Here we measured survival of mammalian cells harbouring $0^{6} \mathrm{MeG}$ adducts in their genomic DNA in the presence and absence of eATL, and it is reasonable to posit that the DNA damage is processed and signals death in a way that is not identic to E. coli. Therefore the data reported here do not contradict findings obtained with bacteria. Given that a functional homologue of ATL that might act as a backup protection mechanism against $\mathrm{O}^{6} \mathrm{MeG}$ has not so far been reported in mammalian cells, it is reasonable to speculate that cell death triggered by $\mathrm{O}^{6} \mathrm{MeG}$, which was left unrepaired by MGMT, is a process that serves to remove $0^{6} \mathrm{MeG}$ harbouring cells from the population.

\section{Conflict of interest}

\section{No conflict of interest.}

\section{Acknowledgement}

We thank Vanessa Steinmetz and Anna Frumkina for technical assistance. Work of BK was supported by DFG KA724. GPM thanks Cancer Research, UK and CHEMORES for support.

\section{References}

[1] F. Drablos, E. Feyzi, P.A. Aas, C.B. Vaagbo, B. Kavli, M.S. Bratlie, J. Pena-Diaz, M. Otterlei, G. Slupphaug, H.E. Krokan, Alkylation damage in DNA and RNA - repair mechanisms and medical significance, DNA Repair 3 (2004) 1389-1407.

[2] D. Fu, J.A. Calvo, L.D. Samson, Balancing repair and tolerance of DNA damage caused by alkylating agents, Nat. Rev. Cancer 12 (2012) 104-120.

[3] A. Loveless, Possible relevance of O-6 alkylation of deoxyguanosine to the mutagenicity and carcinogenicity of nitrosamines and nitrosamides, Nature 223 (1969) 206-207.

[4] D. Toorchen, M.D. Topal, Mechanisms of chemical mutagenesis and carcinogenesis: effects on DNA replication of methylation at the O6-guanine position of dGTP, Carcinogenesis 4 (1983) 1591-1597.

[5] N. Mojas, M. Lopes, J. Jiricny, Mismatch repair-dependent processing of methylation damage gives rise to persistent single-stranded gaps in newly replicated DNA, Genes Dev. 21 (2007) 3342-3355.

[6] K. Ochs, B. Kaina, Apoptosis induced by DNA damage O6-methylguanine is Bcl2 and caspase-9/3 regulated and Fas/caspase- 8 independent, Cancer Res. 60 (2000) 5815-5824.

[7] G.P. Margison, M.F. Santibanez Koref, A.C. Povey, Mechanisms of carcinogenicity/chemotherapy by O6-methylguanine, Mutagenesis 17 (2002) 483-487.

[8] S. Quiros, W.P. Roos, B. Kaina, Processing of O6-methylguanine into DNA double-strand breaks requires two rounds of replication whereas apoptosis is also induced in subsequent cell cycles, Cell Cycle 9 (2010) 168-178.

[9] B. Kaina, M. Christmann, S. Naumann, W.P. Roos, MGMT: key node in the battle against genotoxicity, carcinogenicity and apoptosis induced by alkylating agents, DNA Repair 6 (2007) 1079-1099.

[10] W.P. Tong, M.C. Kirk, D.B. Ludlum, Formation of the cross-link 1-[N3deoxycytidyl),2-[N1-deoxyguanosinyl]ethane in DNA treated with N,N'-bis(2chloroethyl)-N-nitrosourea, Cancer Res. 42 (1982) 3102-3105.

[11] T. Nikolova, F. Hennekes, A. Bhatti, B. Kaina, Chloroethylnitrosourea-induced cell death and genotoxicity: cell cycle dependence and the role of DNA doublestrand breaks, HR and NHEJ, Cell Cycle 11 (2012) 2606-2619.

[12] A.E. Pegg, Multifaceted roles of alkyltransferase and related proteins in DNA repair, DNA damage, resistance to chemotherapy, and research tools, Chem. Res. Toxicol. 24 (2011) 618-639.

[13] S.J. Pearson, J. Ferguson, M. Santibanez-Koref, G.P. Margison, Inhibition of 06-methylguanine-DNA methyltransferase by an alkyltransferase-like protein from Escherichia coli, Nucleic Acids Res. 33 (2005) 3837-3844.
[14] S.J. Pearson, S. Wharton, A.J. Watson, G. Begum, A. Butt, N. Glynn, D.M. Williams, T. Shibata, M.F. Santibanez-Koref, G.P. Margison, A novel DNA damage recognition protein in Schizosaccharomyces pombe, Nucleic Acids Res. 34 (2006) 2347-2354.

[15] O.J. Wilkinson, V. Latypov, J.L. Tubbs, C.L. Millington, R. Morita, H. Blackburn, A. Marriott, G. McGown, M. Thorncroft, A.J. Watson, B.A. Connolly, J.A. Grasby, R. Masui, C.A. Hunter, J.A. Tainer, G.P. Margison, D.M. Williams, Alkyltransferase-like protein (Atl1) distinguishes alkylated guanines for DNA repair using cation-pi interactions, Proc. Natl. Acad. Sci. U. S. A. 109 (2012) $18755-18760$.

[16] G.P. Margison, A. Butt, S.J. Pearson, S. Wharton, A.J. Watson, A. Marriott C.M. Caetano, J.J. Hollins, N. Rukazenkova, G. Begum, M.F. Santibanez-Koref, Alkyltransferase-like proteins, DNA Repair 6 (2007) 1222-1228.

[17] G. Mazon, G. Philippin, J. Cadet, D. Gasparutto, R.P. Fuchs, The alkyltransferaselike ybaZ gene product enhances nucleotide excision repair of $\mathrm{O}(6)$ alkylguanine adducts in E. coli, DNA Repair 8 (2009) 697-703.

[18] J.L. Tubbs, J.A. Tainer, Alkyltransferase-like proteins: molecular switches between DNA repair pathways, Cell. Mol. Life Sci. 67 (2010) 3749-3762.

[19] J.L. Tubbs, V. Latypov, S. Kanugula, A. Butt, M. Melikishvili, R. Kraehenbuehl O. Fleck, A. Marriott, A.J. Watson, B. Verbeek, G. McGown, M. Thorncroft, M.F. Santibanez-Koref, C. Millington, A.S. Arvai, M.D. Kroeger, L.A. Peterson, D.M. Williams, M.G. Fried, G.P. Margison, A.E. Pegg, J.A. Tainer, Flipping of alkylated DNA damage bridges base and nucleotide excision repair, Nature 459 (2009) 808-813.

[20] V.F. Latypov, J.L. Tubbs, A.J. Watson, A.S. Marriott, G. McGown, M. Thorncroft, O.J. Wilkinson, P. Senthong, A. Butt, A.S. Arvai, C.L. Millington, A.C. Povey, D.M. Williams, M.F. Santibanez-Koref, J.A. Tainer, G.P. Margison, Atl1 regulates choice between global genome and transcription-coupled repair of O(6)-alkylguanines, Mol. Cell 47 (2012) 50-60.

[21] C.S. Chen, E. Korobkova, H. Chen, J. Zhu, X. Jian, S.C. Tao, C. He, H. Zhu, A proteome chip approach reveals new DNA damage recognition activities in Escherichid coli, Nat. Methods 5 (2008) 69-74.

[22] G. Mazon, G. Philippin, J. Cadet, D. Gasparutto, M. Modesti, R.P. Fuchs Alkyltransferase-like protein (eATL) prevents mismatch repair-mediated toxicity induced by 06-alkylguanine adducts in Escherichia coli, Proc. Natl. Acad. Sci. U. S. A. 107 (2010) 18050-18055.

[23] T. Hayashi, M. Takao, K. Tanaka, A. Yasui, ERCC1 mutations in UVsensitive Chinese hamster ovary (CHO) cell lines, Mutat. Res. 407 (1998) 269-276.

[24] R.D. Wood, H.J. Burki, Repair capability and the cellular age response for killing and mutation induction after UV, Mutat. Res. 95 (1982) 505-514.

[25] J. Dosch, M. Christmann, B. Kaina, Mismatch G-T binding activity and MSH2 expression is quantitatively related to sensitivity of cells to methylating agents, Carcinogenesis 19 (1998) 567-573.

[26] B. Kaina, G. Fritz, S. Mitra, T. Coquerelle, Transfection and expression of human 06-methylguanine-DNA methyltransferase (MGMT) cDNA in Chinese hamster cells: the role of MGMT in protection against the genotoxic effects of alkylating agents, Carcinogenesis 12 (1991) 1857-1867.

[27] S.C. Naumann, W.P. Roos, E. Jost, C. Belohlavek, V. Lennerz, C.W. Schmidt, M. Christmann, B. Kaina, Temozolomide- and fotemustine-induced apoptosis in human malignant melanoma cells: response related to MGMT, MMR, DSBs, and p53, Br. J. Cancer 100 (2009) 322-333.

[28] W.P. Roos, A. Binder, L. Bohm, Determination of the initial DNA damage and residual DNA damage remaining after 12 hours of repair in eleven cell lines at low doses of irradiation, Int. J. Radiat. Biol. 76 (2000) 1493-1500.

[29] G.P. Margison, J. Heighway, S. Pearson, G. McGown, M.R. Thorncroft, A.J. Watson, K.L. Harrison, S.J. Lewis, K. Rohde, P.V. Barber, P. O’Donnell, A.C. Povey, M.F. Santibanez-Koref, Quantitative trait locus analysis reveals two intragenic sites that influence O6-alkylguanine-DNA alkyltransferase activity in peripheral blood mononuclear cells, Carcinogenesis 26 (2005) 1473-1480

[30] A. Westerveld, J.H. Hoeijmakers, M. van Duin, J. de Wit, H. Odijk, A. Pastink, R.D. Wood, D. Bootsma, Molecular cloning of a human DNA repair gene, Nature 310 (1984) 425-429.

[31] A.J. Deans, S.C. West, DNA interstrand crosslink repair and cancer, Nat. Rev. Cancer 11 (2011) 467-480

[32] A.V. Knizhnik, W.P. Roos, T. Nikolova, S. Quiros, K.H. Tomaszowski, M. Christmann, B. Kaina, Survival and death strategies in glioma cells: autophagy, senescence and apoptosis triggered by a single type of temozolomide-induced DNA damage, PLoS ONE 8 (2013) e55665.

[33] R. Goth-Goldstein, Inability of Chinese hamster ovary cells to excise 06alkylguanine, Cancer Res. 40 (1980) 2623-2624.

[34] M. Lobrich, A. Shibata, A. Beucher, A. Fisher, M. Ensminger, A.A. Goodarzi, O. Barton, P.A. Jeggo, gammaH2AX foci analysis for monitoring DNA doublestrand break repair: strengths, limitations and optimization, Cell Cycle 9 (2010) 662-669.

[35] P.L. Olive, D. Wlodek, J.P. Banath, DNA double-strand breaks measured in individual cells subjected to gel electrophoresis, Cancer Res. 51 (1991) 4671-4676. 